\title{
Filial Piety: From the Perspective of Indonesian Young Adults
}

\author{
Rahmi Setiyani ${ }^{1}$, Carol Windsor ${ }^{2}$ \\ ${ }^{I}$ Nursing Department, Faculty of Health Sciences, Universitas Jenderal Soedirman, Indonesia \\ ${ }^{2}$ School of Nursing, Faculty of Health, Queensland University of Technology, Australia \\ Corresponding Author: Rahmi Setiyani (rahmi.setiyani@unsoed.ac.id)
}

Received: 24 November 2018

Revised: 23 May 2019

Accepted: 25 May 2019

\begin{abstract}
Background: Filial piety refers to expectations for children to respect parents and fulfill care responsibility, including provide direct care and support them in their old age. However, socio-demographic changes might shape how young generation would see and practice the value of filial responsibility in parent's old age.

Purpose: This study aimed to explore the meaning of filial responsibility among young adults within the social context of Indonesia.

Methods: Symbolic interactionism formed the framework for this study. The constructivist grounded theory method guided the analysis of the data obtained from indepth interviews with eight university students. The participants were selected using a purposive and snowball sampling technique with the following criteria: 18 years old or over, currently enrolled as a student and had living parents.

Results: The result showed that redefining the meaning of filial responsibility was obtained as the main theme which linked all four categories: 'I am the one', 'not institutional care', 'the gendering of caregiving', and 'it is okay to do so'. The findings revealed that the value of filial responsibility was still upheld by Indonesian young people. However, their views had been changed somewhat from the traditional practices which were family oriented and highly gendered to a more contemporary form where caregiving was extended to non-family caregivers and supposed to be less gendered in practice.

Conclusion: This study offers an insight into the shifting patterns in elderly caregiving and support in Indonesia. The findings also indicate the need to further promote gender equality in elderly caregiving.
\end{abstract}

Keywords: Elderly caregiving; filial responsibility; population aging; young adults

\section{BACKGROUND}

There is a rapidly increasing aging population worldwide. In Indonesia, the proportion of persons aged 60 years or over in 2017 represented $9 \%$ of the population, and by 2050 the country will be among the top ten countries with the largest number of elderly persons (United Nations, 2017 a ). Population aging is projected to have a profound effect on the support ratio. United Nations $\left(2017^{\mathrm{b}}\right)$ reported that the support ratio for an older Indonesian in 2010 was 13 . However, this number is projected to continue declining, and by 2035, will have fallen to 6.4 (United Nations Population Fund [UNFPA], 2014). These low ratios highlight the economic and political burden that many countries are 
likely to deal with in the coming decades regarding health care, pensions, and social protections for a growing older population. The Indonesian government has taken significant steps to protect the health of all citizens through the implementation of the national health protection program. However, this is not followed by the progress in economic and social protection, especially those working in the informal sector (Widjaja \& Simanjuntak, 2010). Consequently, support for elderly people will be affected.

In Indonesia, long term support for older people is usually provided by family members, particularly adult children, because government support is limited (Kadar, Francis, \& Sellick, 2013). Besides, the presence of value of filial piety has also shaped this reality. Filial piety typically refers to expectations for children to respect parents and fulfill care obligations towards them. These may include providing direct care and supporting parents in their old age (Chappell \& Funk 2011). However, social changes, including rural to urban migration, changes in the living arrangement, the decline in family size and globalization, female participation in the labor force and changes to family size and structure, have raised concern over the availability of the support (Kadar, Francis, \& Sellick, 2013). These changes may also shift how people would see and practice the value of filial responsibility.

The current issue of long term family support for older people elderly parents in Indonesia remains under investigation. Therefore, to determine future needs regarding elderly care in Indonesia, it appears timely to explore the current situation by investigating young people's perceptions of their responsibilities in the provision of care for older people, specifically for elderly parents. The view of the young generation would be important since they will experience the social and cultural changes and be prospective caregivers for their parents in old age.

\section{PURPOSE}

This study aimed to explore the meaning of filial responsibility as constructed by young people in Indonesia.

\section{METHODS}

\section{Theoretical approach}

This study used symbolic interactionism as the theoretical framework to depict the meaning of filial responsibility as perceived by young people in the social context of Indonesia. This theoretical approach is situated within a broad tradition dedicated to the study of human society and human conduct and with a specific focus on meaning formation through social interaction (Blumer, 1969). There are three basic assumptions of symbolic interactionism: (1) people act toward things on the basis of the meanings that things have for them; (2) the meaning of things is derived from social interaction with others; and (3) meaning is handled in and modified through an interpretative process (Blumer, 1969). In Indonesia, people engage with norms and social expectations regarding a responsibility to look after elderly parents. Symbolic interactionism offers a perspective to understand young people's perception of filial responsibility by getting inside the process of meaning construction, examining the process from the perspective of those who engage in the construction process and taking into account various factors 
in the meaning construction process, rather than simply examining the presence of various internal and external factors or any changes in their social world.

\section{Participants}

Participants were undergraduate students in a state university in Central Java, Indonesia. University students were selected because they possibly had to negotiate dilemmas in the future over choices between employment and caring responsibilities. Participants were selected using purposive and snowball sampling techniques. They were screened for their eligibility to participate in this study based on the criteria that they were 18 years old or over, currently enrolled as a student at the university where the study was conducted proven by student ID card and had living parents (one or both).

\section{Data collection}

In-depth interview was employed to generate understanding about an individual's interpretation of filial responsibility. This method was chosen since it suited the methodological and theoretical position of this study. In-depth interviewing enables the researcher to understand an individual point of view and is closely related to the development of the interpretive research tradition (Minichiello, Aroni, Timewell \& Alexander, 1995). The interview guide was formulated using the following steps: (1) writing down the larger research questions of the study and outline the major areas that are relevant, (2) developing questions within each of these broad areas and adjust them to fit kinds of respondents, (3) adjusting the language according to the respondents, (4) developing open-ended type of questions to elicit more detailed responses, and (5) arranging questions to meet the logical flow of the interview.

The interview was face to face and took place in a mutually agreed upon setting. The interviews were conducted in Bahasa Indonesia and audio-recorded, each lasting for 55 minutes to 70 minutes. Throughout each interview session, the researchers addressed the topic and questions to guide the discussion. The interview was started using an open-ended starting question, such as "What do you think are the responsibilities of children toward their elderly parents?" When participants introduced particular ideas, follow up questions would be asked to explore. Following were a few examples of the questions to guide the discussion "In your opinion, who should provide the support?", "Who should assume the responsibility?", "How do you think the responsibility should be demonstrated?", "Can you explain other ways to demonstrate the filial responsibility?", "Do you think that the practice of support provision will change in the future?".

\section{Ethical considerations}

Ethical approval for the research was gained from the Human Research Ethics Committee of the Queensland University of Technology (QUT). Participants were given information about the aims and the nature of the research, including the right to refuse and withdraw from participation at any time, before signing the written consent. Confidentiality of the participant was preserved by limiting access to the data only to the researcher and the supervisory team. For securing the anonymity, the participant's name was replaced with an ID number in the data labeling. 


\section{Data analysis}

Data were transcribed verbatim by the researchers after the completion of each interview. Transcriptions were in Bahasa Indonesia to preserve the originality of meaning. When the data analysis was finished, the codes and key quotation were translated into English. Constructivist grounded theory methods guided the process of data analysis. The analytical process began through the process of coding, which was conducted in three phases: initial, focused, and theoretical (Charmaz, 2006). Throughout the process of analysis, memos were written in addition to the process of coding to keep the researcher grounded in the data and to increase the level of abstraction of ideas (Charmaz, 2006).

\section{Rigor}

Evaluation criteria, consisting of credibility, originality, resonance, and usefulness, were used to determine the rigor of this study (Charmaz, 2006). To ensure the credibility of the study, the researchers had carefully chosen methodology, participants and data collection method so that it was congruent with a research problem, as well as stayed close to the data during analysis and provided an adequate number of quotation in the report. Regarding originality, this research offered new insights into the process of the social construction of the meaning of filial piety in Indonesian society. There was no published research on perceptions of filial piety within the Indonesian context when this study was conducted. A clear description and direct quotations were provided in the written report so that readers who have no direct experience with the study context can reflect upon the meaning of filial piety in their situation and thus enhanced the resonance of this study. The individual participants might not have a direct benefit from this study. However, it has been indicated that this study provides a better understanding of the current situation and future trend in elderly care in Indonesia.

\section{RESULTS}

The results of the study showed that out of the eight participants, four were females, and four were males. All participants were single and aged of 18-23 years old. All participants had both living parents (father and mother). Majority of them were from Java Island and now living separately with parents (different province or city) due to study. Participants were from various departments (study major).

\section{Redefining the meaning of filial piety}

This study aimed to explore the meaning of filial responsibility as constructed by young people in Indonesia using symbolic interactionism approach. Redefining the meaning of filial piety constituted young people's perceptions of their responsibility in the provision of care for elderly parents. This core category comprised of four categories: 'I am the one', 'not institutional care', 'the gendering of caregiving', and 'it is okay to do so'. The first three categories depicted the traditionally accepted elderly caregiving practice where family members and particularly women assumed the role of a major provider of elderly care. Meanwhile, the last category referred to justifying and accepting less conventional practices of elderly care. 


\section{I am the one}

This category depicts young people's views of the caregiving role. They perceived themselves as the one responsible for caring for parents as they aged. There are five different meaning that the participants attribute to their future caregiver role.

First, the caregiver role is perceived to be an enactment of filial obligation. Fulfilling the filial duty is perceived to be a matter of personal choice that comes voluntarily and with no pressure from anyone.

"I don't think my family; my parents would ever demand me to do that (giving supports, taking care of) as they aged. That is purely my wish" (R.7).

Second, the caregiver role is viewed as a fulfillment of social expectations. The following excerpt indicates the expectation of parents of filial support from children.

"My parents said that children are the only hope they have for support. "If not you (children), who will take care of us in the future?" said my parents" (R.4).

A perceived sense of indebtedness also guides young people in this study to assume the caregiver role and to provide future support for elderly parents. Time to repay their sacrifices indicates a pattern of reciprocal exchange between parents and children whereby children perceive an obligation to repay parents for past sacrifices.

"We have to remember that when we were very young, our parents were so busy taking care of us. So, if now it is time for us to repay their sacrifice, why don't we just do it" (R.1).

Role modeling provides an additional explanation of the construction of caregiver roles among young people in this study. It is common among those living in three-generation households to be exposed to caregiving environments. Thus, in engaging in intense interactions with a caregiving situation, the younger generation has an opportunity to define their own value of intergenerational support and to act accordingly. Participants cited that parents were the role models for elderly care.

"I'd like to do what my parents did for their parents (looking after them)" (R.2).

Finally, young people perceived that assuming filial responsibility was a demonstration of adherence to religious teachings as it was cited in the holy book.

"It has been described in the Quran (The Muslim holy book) about children duties toward parents, and I will do my best to observe it" (R.4).

\section{Not institutional care}

This category highlights young people's understanding of institutional care. It appears from the study that this form of service has not yet been largely accepted as an alternative for elderly care in Indonesia for various reasons. Nursing home placement, in the participants' view, is the converse of a belief in filial obligation. As they perceived 
that institutionalization violates the value of filial piety, they were critical of the formal use of care and endorsed care of elderly parents at home.

"It (admitting parent into a nursing home) is contrary to my belief about filial piety" (R.1).

The hesitation of young people to use formal care services as an alternative care arrangement for elderly parents is also shaped by the view that elderly care is a matter of family responsibility. Institutional care service, in their view, is aimed at elderly people who have no family.

"When they still have family, why do they have to live in a nursing home?" (R.8).

A perceived negative judgment from the society and lack of benefits further hinder adult children from considering institutional care as a future care arrangement. The following excerpts reflect these views.

"People will see me cynically. Though they might not show it explicitly. I thought I would have a bad image from the society. How could a child send the parents to a nursing home?" (R.1)

"They may receive good physical care there (at the nursing home), but how about their psychological needs?" (R.7)

\section{The gendering of caregiving}

This category suggests that women in Indonesia are still widely expected to play a dominant role in elderly caregiving.

"My mother took care of my great grandpa. Sometimes my aunt helped her" (R.3).

Participants perceived that female and male adult children were assigned to distinct roles based on who had the primary role in the care and how care tasks were shared.

"Men are less likely doing something dealing with the human body such as bathing, toileting, and so on. They prefer buying medicine, taking to doctor, giving emotional support, or doing some other things" (R.2).

The traditional gendered-based division on labor, which expects women to deal with domestic works and the belief that they have natural caregiver personality are suggested to construct this reality.

"Men are expected to work for their family, while women have an obligation to take care of household responsibilities, children, husband and also parents" (R.3). 
"Elderly parents are usually looked after by daughters. I don't know why. It's probably because they are more skillful in doing such things (caregiving tasks) than sons. Moreover, they are very patient and attentive" (R.5).

\section{It is okay to do so}

This last category depicts the less traditional way to enact the filial duty in Indonesia context. Adult children in this study start to revisit family as the primary care provider and consider using alternatives of elderly care, particularly paid caregiver as they see an inability to assume the caregiving role in the future because of work responsibility.

"Actually, it is okay to do so (hiring a paid worker). It doesn't mean that they (children) release their responsibility to take of the parents. They may do so as they are busy working" (R.2).

Further, the demonstration of filial piety has shifted from day to day care to the symbolic one, such as paying a visit, as the phenomenon of migration among young people increases.

"If my parents are getting older, and I am working out of my hometown, I will frequently pay them a visit" (R.4).

That the traditional gender role in Indonesia is being challenged was reflected in the view of the female participants that the responsibility to care for elderly parents should be equally distributed between female and male children.

"There should be equality between men and women with regard to caregiving responsibility. Caregiving tasks should be shared" (R.1).

The core category of Redefining the meaning of filial responsibility captures the overarching perception of filial responsibility among young people in Indonesia. Redefining the meaning of filial responsibility reflects the process whereby young people give new meaning to children's responsibilities to their parents. They shifted the traditional practices in elderly caregiving, which is family focused and highly gendered and then constructed a new perspective of filial piety that moves beyond family and gender boundaries.

\section{DISCUSSION}

Changes in socioeconomic feature have left questions regarding the future of elderly caregiving in Indonesia. The changes might also affect how the value of filial responsibility perceived and enacted by the young generation. Filial responsibility (filial piety) is generally defined as a value emphasizing respect, honor, loyalty, and obligations of children to their parents (Tsai, Chen \& Tsai, 2008). Although the discourse of filial piety was more pronounced in Chinese cultural contexts, it was subtly echoed in some studies in other Asian societies (Beh \& Folk, 2013; Chan, 2017). The present study makes several advances towards a better understanding of the meaning of filial piety in Indonesia context. 
Young people in Indonesia initially defined filial piety in ways similar to previous generations. Elderly care was family focused whereby family members were the only persons deserving to provide the care for elderly parents. Involving non-family members in care was perceived as a violation of filial values. When elderly parents were cared for by 'non-blood' relatives, it was often considered to be something shameful and to be avoided (Schröder-Butterfill \& Fithry, 2014). This caregiving norm could be found in some cultures, particularly those with a collectivistic orientation. However, in other culture, caregiving responsibilities go beyond immediate family members and involve kinship relationships, for example, close friends and neighbors (Pharr, Francis, Terry, \& Clark, 2014).

Regarding the care arrangement, home in this study was considered to be the ideal place where care would be provided, and caregivers would co-reside with care recipients. The previous study suggested that intergenerational co-residence was an exemplification of filial piety. The stronger the filial piety expressed by adult children, the more likely they would co-reside with their parents (Zhang, Gu, \& Luo, 2014). For the study participants, institutional care was generally unacceptable, and caring responsibilities sat firmly in the domain of women's work. As such, the involvement of men in care was understood as limited to less intense and non-direct care tasks. Thus, there was a clear boundary between being filial and non-filial regarding who performs the care and where the care takes place. Briefly, to be a filial child, one would need to commit to being caregivers of parents in the future, provide direct care to their elderly parents, deliver the care at home and assume clear gendered caring roles. In most cultures, caregiving was primarily prescribed based on the female gender, some regulated by rules which assign a strict hierarchy designating specific female family members, but others don't (Pharr et al., 2014).

However, the participants had also realized that in certain situations, the aboveexpressed meaning of filial piety did not readily fit with their reality. Social change, namely migration and the increasing participation of women in paid employment brought about by globalization and economic development, have given rise to challenges to the traditional practices of filial piety. Although young people in this study were not actual caregivers, a sense of ambivalence was obvious as they identified potential conflicts between care and work responsibilities. On the one hand, they wished to retain the responsibility to care for elderly parents but, on the other hand, realized that migration and participation in the workforce are inevitable and desired features of their futures. Migration became a strategy to improve the welfare of the family (Liu, 2014). For adult daughters, participation in paid work was obviously problematic since they were expected to provide direct physical care for elderly parents. The previous study suggested that industrialization and urbanization have contributed to some new caregiving crises. Adult children are becoming less available to provide a form of assistance that requires them to be physically present (Chen, 2011). However, a study suggested that it was not the event of migration that has a detrimental effect on the older generation, but rather the breakdown of the webs of interdependence and reciprocity (Liu, 2014). 
Where such conflict arises, young people are likely to re-examine previously held meanings of filial piety and construct new meanings. The perception that elderly parents should be taken care of by family members is no longer valid. In certain circumstances, such as when children are engaged in work, involving non-family members in elderly caregiving is no longer considered to be un-filial behavior. The boundary between being filial and non-filial in regards to who performs the care becomes less significant. This is reinforced in a study where nursing home placement has been considered to be alternatives for elderly care to cope with family caregiving crisis (Chen, 2011). The study suggested that older residents have become more understanding of their children's lives and are willing to accept institutional caregiving

Furthermore, filial children do not always have to co-reside and provide direct care. When children live away from parents, filial piety can be demonstrated in symbolic ways such as paying visits and sending remittances without undermining filial meaning. This situation confirms a previous study suggesting that the increased urban and transnational labor migration, especially adult daughter has affected adult children to practice filial duty in diverse ways such as financial remittance and regular communication (Chan, 2017).

Care work has been long defined as women's labor domain. An ethnographic study in rural Indonesia revealed that caring responsibility was likely to assume by daughters rather than sons, and it was more profound in matrilineal society (Schröder-Butterfill \& Fithry, 2014). However, the gendering of caregiving is likely being revisited in this present study. Increasingly, it is considered that the responsibility for caregiving should be equal between genders and not solely a daughter's responsibility. In attaining higher education, female adult children in this study saw expanded opportunities to work outside the home. Female labor participation in Indonesia has increased from $44 \%$ in 1990 to 51\% in 2017 (World Bank, 2017). They foresaw that they would need to negotiate their caregiving roles, including task divisions. Previous studies indicated that, although both genders were strongly expected to support their elderly parent, task divisions tended to be gendered, even among sons who identified themselves as the main caregiver. The daughter was more likely to provide direct daily care, as opposed to sons who more likely to play indirect organizational roles, including monetary support (Lylod-Sherlock et al., 2018; Schröder-Butterfill \& Fithry, 2014). Changes in attitudes of male adult children toward care are also integral to the process of redefinition of gender roles. Similar to breadwinning, they see that family caregiving should be considered to be a less gendered task. Even though there was a willingness, it seems that gender role in regards to caregiving was quite difficult to change. A study in transnational families found that the men who either migrate or stay behind acted as reluctant caregivers, while the women remained obliged to undertake care work (Fan \& Parreñas, 2018).

The appearance of new meanings of filial piety does not mean that the processes of meaning construction have ended, but rather, it is an ongoing process. As long as individuals engage in interaction with diverse others and confront changes in their social worlds, filial piety will be continuously undergoing modification in its meaning. In the present study, the core category implies a shift in the meaning of the obligation to care 
for elderly parents somewhat from the conventional practices, which are family oriented and highly gendered, to a more contemporary form where caregiving is extended to non-family caregivers and thus appears to be less gendered in practice. A traditional perspective that views elderly caregiving to be exclusively the responsibility of family members and particularly woman has been challenged in this study. Change in the meaning of filial piety was also shown in previous studies. For example, Liu (2014) found a shift from the traditional pattern of elderly caregiving, which focused on the will and welfare of the elderly to mutual support between generations.

There are a number of limitations to consider in this study. First, due to time constraints, only eight interviews were conducted. Although an in-depth interview method was employed, the researcher considered that some issues could not be fully explored with this number of interviews. Second, the researcher had limited time to build a trusting relationship with participants prior to the commencement of an interview. Thus, it was possible that there might have been some hesitation on the part of the participants to share personal views and experiences with the researcher. Further, due to the choice of participants, the findings of this study only reflect the meaning of filial responsibility from the perspective of adult children who are expected to be caregivers in the future and who have a high level of education resulting in the increase job prospects. The perspectives of those who are in actual caregiving situations were not captured in this study.

\section{CONCLUSION}

The research findings have suggested that filial piety is an important value in Indonesia, and it continues to be upheld by society. However, the meaning has shifted alongside a changing social world. It is therefore important that health care professionals understand and appreciate the value of filial piety as it is perceived by an individual to provide culturally sensitive interventions. The hesitation in using formal care services, particularly institutional care, indicates the need to develop alternatives for elderly care, such as home care and day care services run by health professionals. Using these kinds of services, elderly people can receive sufficient support without relocating to nursing homes. This study also reveals the issue of gender differences in caregiving in Indonesian society. The findings imply the need to promote equality between men and women regarding caregiving responsibility.

\section{ACKNOWLEDGMENT}

We thank the anonymous participants for their participation and all parties for their endless support. We also thank Clint Douglas for his support in this study.

\section{CONFLICT OF INTEREST}

The authors declare no conflict of interest.

\section{REFERENCES}

Beh, L. S. \& Folk, J. Y. (2013). A study of filial piety practice in Malaysia: relationship between financial well-being and filial piety. African Journal of Business Management, 7(38), 3895-3902. doi: 10.5897/AJBM10.424 
Blumer, H. (1969). Symbolic Interactionism: Perspective and Method. Englewood Cliffs, N.J.: Prentice-Hall.

Chan, C. (2017). "Not always 'left-behind:' Indonesian adolescent women negotiating transnational mobility, filial piety, and care," The Asia Pacific Journal of Anthropology, 18 (3), 246-263. doi: 10.1080/14442213.2017.1311372

Chappell, N. L., \& Funk, L. (2011). Filial caregivers; diasporic Chinese compared with homeland and hostland caregivers. Journal of cross-cultural gerontology, 26(4), 315-329.

Charmaz, K. (2006). Constructing Grounded Theory: A Practical Guide Through Qualitative Analysis. London: SAGE Publications.

Chen, L. (2011). Elderly residents' perspective on filial piety and institutionalization in Shanghai. Journal of Intergenerational Relationships, 9(1), 53-68. doi: 10.1080/15350770.2010.544209

Fan, Y., K., \& Parreñas, R. S. (2018) Who cares for the children and the elderly? gender and transnational families. In: Ducu V., Nedelcu M., Telegdi-Csetri A. (eds) Childhood and Parenting in Transnational Settings. International Perspectives on Migration, vol 15. Springer: Cham.

Lloyd-Sherlock, P., Mayston, R., Acosta, A., Gallardo, S., Guerra, M., Sosa, A. L., Montes de Oca, V \& Prince, M. (2018). Allocating family responsibilities for dependent older people in Mexico and Peru. The Journal of Development Studies, 54(4), 682-701, doi: 10.1080/00220388.2017.1308489

Kadar, K. S., Francis, K., \& Sellick, K. (2013). Ageing in Indonesia: health status and challenges for the future. Ageing International, 38, 261-270. doi 10.1007/s12126012-9159-y

Liu, J. (2014). Ageing, migration and familial support in rural China. Geoforum, 51, 305-312, doi: 10.1016/j.geoforum.2013.04.013

Minichiello, V., Aroni, R., Timewell, E., \& Alexander, L. (1995). In-Depth Interviewing: Principles, Techniques, Analysis (2 ed.). Melbourne: Longman.

Pharr, J. R., Francis, C. D., Terry, C., \& Clark, M. C. (2014). Culture, caregiving, and health: Exploring the influence of culture on family caregiver experiences. ISRN Public Health, doi: 10.1155/2014/689826

Schröder, E \& Fithry, T. S. (2014) Care dependence in old age: Preferences, practices, and implications in two Indonesian communities. Ageing Society, 34(3), 361-387, doi: $10.1017 / \mathrm{S} 0144686 \mathrm{X} 12001006$

Tsai, H. H., Chen, M. H., \& Tsai, Y. F. (2008). Perception of filial piety among Taiwanese university students. Journal of Advanced Nursing, 63(3), 284-290.

United Nations Population Fund (UNFPA). (2014). UNFPA Monographs Series No.1: Indonesia on the Threshold of Population Ageing. Indonesia: UNFPA.

United Nations $\left(2017^{\mathrm{a}}\right)$. World Population Ageing. New York: United Nations.

United Nations $\left(2017^{\mathrm{b}}\right)$. World Population Prospects The 2017 Revision. New York: United Nations

Widjaja, M. and R. A. Simanjuntak (2010), 'Social Protection in Indonesia: How Far Have We Reached?', in Asher, M. G., S. Oum and F. Parulian (eds.), Social Protection in East Asia - Current State and Challenges. ERIA Research Project Report 2009-9, Jakarta: ERIA. pp.157-181.

World Bank. (2017). World Development Indicators. Retrieved from https://data.worldbank.org/indicator/SL.TLF.CACT.FE.ZS 
Nurse Media Journal of Nursing, 9(1), 2019, 57

Zhang, Z., Gu, D., \& Luo, Y. (2014). Coresidence with elderly parents in contemporary China: The role of filial piety, reciprocity, socioeconomic resources, and parental needs. Journal of Cross Cultural Gerontology, 29, 259-276. doi: 10.1007/s10823014-9239-4 